\title{
Margarita, está linda la mar: una reflexión sobre la construcción binaria hegemonía versus subalternidad*
}

Fecha de recepción: 22 de enero de 2018

Fecha de aprobación: 25 de junio de 2019

\section{Resumen}

El presente artículo de reflexión estudia la obra Margarita, está linda la mar (1998) del escritor nicaragüense Sergio Ramírez, a la luz de su relación con el contexto (teoría poscolonial). Desde este punto de vista, se propone un análisis sobre la relación dicotómica hegemonía versus subalternidad, donde se revelan huellas coloniales a partir de los proyectos hegemónicos. Así, por un lado, se demuestra la presencia hegemónica - política y militar- mediante el cotejo de los dos escenarios históricos representados, como consecuencia de la intervención militar por parte de fuerzas militares nacionales y extranjeras, que representaron el control y la represión de todo un país; y, por otro lado, las reflexiones en torno a la condición de subalternidad, vista como expresión y contraparte de la dominación encarnada o incorporada de los sujetos oprimidos.

Palabras clave: poscolonial, hegemonía, subalternidad, dominación, opresión, historia.

Citar: Méndez Sánchez,D.V. (julio- diciembre de 2019). Margarita, está linda la mar: una reflexión sobre la construcción binaria hegemonía versus subalternidad. La Palabra, (35) 101-114. do: https://doi.org/10.19053/01218530.n35.2019.8975

\section{Diana Verónica Méndez Sánchez}

Universidad Popular del Cesar

Magíster en Literatura Hispanoamericana y del Caribe. Docente ocasional de tiempo completo e investigadora de la Universidad Popular del Cesar. 구 https://orcid. org/0000-0002-3160-7281

dianamendez@unicesar.edu.co

*Artículo de reflexión 


\title{
Margarita, How Beautiful the Sea: a Reflection on the Binary Construction Hegemony Versus Subordination
}

\begin{abstract}
This paper studies Margarita, está linda la mar [Margarita, How Beautiful the Sea] (1998) by Nicaraguan writer Sergio Ramírez in regards to his relation with the context (postcolonial theory). From this point of view, an analysis in the dichotomous hegemony versus subordination is proposed, where colonial influence is revealed from hegemonic projects. So, on the one hand it is demonstrated the hegemonic presence — politic and military - through the comparison of the two historical scenarios represented, as a consequence of the military intervention on the part of the national and foreign military forces that represented the control and the repression of a whole country, and, in the other hand the reflections around the condition of subordination seen as an expression and opposing party of the embedded and integrated domination of the oppressed individuals.
\end{abstract}

Keywords: postcolonial, hegemony, subordinating, domination, oppression, history. 


\section{Introducción}

El interés por reconocer la identidad del ser americano, ha llevado a que la literatura hispanoamericana se ocupe de varios aspectos de su propia realidad, en la cual el pasado, su historia, desempeña un papel trascendental. En buena parte de la literatura escrita en Hispanoamérica, ha predominado la evocación del pasado, marcada por encuentros y desencuentros culturales, y por una tradición que es producto de la mezcla de tradiciones originales de América y de otros continentes, en fin, por la historia y por el sentido de una condición histórica y cultural híbrida. Como consecuencia, retomar el pasado ha terminado por convertirse para muchos escritores en una urgencia, una necesidad, un intento por encontrar los orígenes, y por situar al ser americano en algún lugar del pasado y el presente.

Podría decirse entonces que la relación de la literatura hispanoamericana con la historia es de siempre. Raymond Souza (1988) lo afirma cuando, en la primera parte de su estudio sobre la historia de la novela hispanoamericana, plantea que «el deseo de interpretar o entender el pasado ha estado presente en la literatura latinoamericana desde su iniciación» (p. 11). Esto explica que las relaciones entre la novela y la historia en América Latina se inician prác- ticamente desde las colonias americanas y se van desarrollando de forma continua, adoptando las características marcadas por las corrientes literarias impuestas en el contexto de su escritura, pues entre muchos escritores ha existido plena conciencia de este interrogante, convirtiéndose así en leit motiv de la literatura hispanoamericana.

Sin embargo, cuando la novela comienza a definirse durante la primera mitad del siglo $\mathrm{XX}$, confirmándose con el boom latinoamericano de los sesenta, y marcada por las nuevas técnicas escriturales y recursos narrativos puestos en boga, es que toma un carácter completamente renovado, donde la historia se muestra desde la multiplicidad de discursos, creando al mismo tiempo nuevos lenguajes fundados en la paradoja, la burla, la ironía, la alteridad, la refutación, el anacronismo, la simultaneidad, etc. Así, en la deconstrucción de una realidad histórica, la novela se identifica con las condiciones de producción que la posmodernidad defiende, lo que favorece a conciliar ambos aspectos y condescender a la idea de una novela histórica posmoderna. En términos de lo que Lyotard llamó la condición posmoderna, caracterizada como «una nueva sensibilidad estética, una nueva corriente de pensamiento y un nuevo estado de ánimo que corresponde a una nueva realidad social: el agotamiento o crisis de una modernidad inconclusa» (Pons, 1999, p. 147). Desde esta perspectiva, es posible asistir a la exaltación de una novela madura, con una capacidad de renovación tal, que genera la visión de un "rejuvenecimiento", y no como una simple adecuación a las técnicas contemporáneas de la narrativa.

Así también aparecen, posteriormente, estudios críticos -teoría poscolonial-, cuyos planteamientos se definen por la actitud crítica y reivindicatoria hacia el pasado, en este caso el pasado colonial. El interés poscolonial hacia la historia se explica debido a que el pasado estableció, en gran medida, las estructuras disímiles del poder, conservándose en el presente. Entonces, desde su enfoque, se centra en la intersección entre el pasado y el presente y, por eso, está la posibilidad de examinar y criticar tanto los cambios como la prolongación de los procesos coloniales actuales. Pues, aunque la totalidad de los países no europeos son formalmente descolonizados de sus antiguos imperios, hay actualmente una continuidad de formas de dominación económica, militar y/o cultural, que van desde el centro hacia la periferia, bien sea, entre países de Occidente y los países no occidentales, o bien 
dentro de los países con zonas urbanas desarrolladas y zonas de la periferia.

En este contexto, se ubican algunos países latinoamericanos que, desde una perspectiva poscolonial, conservan procesos coloniales que no desaparecieron con la independencia de España, por lo que aún se les considera territorios poscoloniales. Por tanto, la emancipación de los países latinoamericanos no implicó una verdadera transformación de la realidad para los campesinos, y las condiciones de vida no mejoraron para el mestizo ni para el indígena, ni para el negro. Pues, la situación política y socio-económica de la sociedad formalmente descolonizada, reproduce códigos del antiguo sistema, siguiendo el modelo colonial español, por lo que es posible inferir que el pasado colonial hispanoamericano subsiste en el presente en forma de relaciones desiguales.

En estas condiciones, la novela Margarita, está linda la mar (1998) del escritor nicaragüense Sergio Ramírez, es una narración que contempla importantes parajes significativos de acuerdo con la teoría poscolonial: hegemonía y subalternidad. Aquí, el autor recobra la historia de resistencia contra la dictadura de Anastasio Somoza García en Nicaragua y la vida del poeta insigne Rubén Darío. Su narración constituye una apropiación del espacio discursivo, brindan- do una reflexión posmoderna en que reescribe la historia nicaragüense, contando también la historia silenciada de los que participaron del asesinato contra Somoza. El autor construye un contexto en el que humaniza sus personajes, yuxtaponiendo una conceptualización de sus pensamientos y experiencia cotidiana, con una representación verosímil de los hechos.

Por lo tanto, este artículo demuestra la oposición binaria que existe en la novela, entre hegemonía y subalternidad, donde se revelan huellas coloniales a partir de los proyectos hegemónicos. Por un lado, se demuestra la presencia hegemónica -política y militar- mediante el cotejo de los dos escenarios históricos representados, como consecuencia de la intervención militar por parte de fuerzas militares nacionales y extranjeras que representaron el control y la represión de todo un país; $y$, por otro lado, las reflexiones en torno a la condición de subalternidad, vista como expresión y contraparte de la dominación encarnada o incorporada de los sujetos oprimidos.

\section{Hegemonía versus Subalter- nidad}

Teniendo en cuenta que los conceptos de hegemonía y subalternidad (oposiciones y relaciones) de la teoría literaria poscolonial son fundamentales en el análisis de la novela que se hará en este apartado, es necesario hacer aquí un planteamiento teórico que explique dichos conceptos.

Hegemonía ocupa un lugar preeminente en las cuestiones teóricas y políticas contemporáneas, y ha ejercido gran influencia en el desarrollo de los estudios culturales en varias partes del mundo. El punto de partida de estas discusiones, suele ubicarse en el trabajo Cuadernos de la cárcel $y$ otros trabajos, del teórico italiano Antonio Gramsci (1891-1937), quien dedujo que la hegemonía:

se refiere a las formas de poder que tuvieron las clases dominantes en convencer a ciertos grupos o clases que sus intereses son para el bien de todos. Este mecanismo ideológico no se realiza necesariamente mediante la fuerza o persuasión activa, sino por medio de ejercer poder sobre la economía y los aparatos del estado, los cuales son las instituciones que producen cultura $\mathrm{y}$ conocimiento. (Gramsci en Ashcroft \& Ahluwalia, 2001, p. 77) (traducción mía).

Gramsci plantea la hegemonía como una forma de dominación en la cual la sujeción y la violencia no desaparecen, pero sí coexisten con formas de aceptación del poder y la dominación por parte de los sujetos subalternos. Ejercer el liderazgo 
político o hegemónico no debe contar solamente con el poder y la fuerza material del gobierno, sino también con la aceptación, más o menos, voluntaria de los sujetos dominados; aceptación que es diseminada y adquirida a través de un proceso complejo, en el que la educación, la religión y la cultura desempeñan un papel crucial.

Por lo tanto, el término hegemonía es significativo, desde una perspectiva poscolonial, pues permite comprender la capacidad del poder imperial, e influir en el pensamiento y en el comportamiento de los sujetos dominados mediante la imposición de discursos imperiales, como el orden social y el progreso, los cuales son presentados como intereses comunes.

Subalternidad es un concepto que también adquiere, inicialmente, profundidad teórica en los trabajos de Antonio Gramsci en relación con sus reflexiones sobre la hegemonía. Gramsci contrapone dominación (hegemonía) y subalterni$\mathrm{dad}$, creando una dualidad que acompaña su reflexión teórica. Para Gramsci, la subalternidad se refiere a los grupos que son sometidos a la hegemonía de las clases altas y dominantes de una sociedad, lo cual significa estar en una posición inferior de la jerarquía socio-económica.

El marcado interés por el sujeto subalterno, también es utilizado por Ranajit Guha y Spivak (1988), quienes toman prestado el término gramciano y lo definen "como denominación del atributo general de subordinación en la sociedad, ya sea que esté expresado en términos de clase, casta, edad, género, ocupación, o cualquiera otra forma" (p. 35). Esto con el fin de construir una relectura de la historia e historiografía de la India, y proponer una nueva mirada sobre las relaciones entre hegemonía y dominancia.

Otra definición que revela el interés por el término, es la expresada por Gayatri C. Spivak, quien, en su trabajo Can the Subaltern Speak? (2009), plantea la preocupación en torno al mensaje de los subalternos, a su carencia de enunciación e interlocución, es decir, la imposibilidad de los subalternos para participar como agentes en la dinámica de la hegemonía. Por tanto, subalterno es quien no presenta ningún discurso, ninguna autonomía que le permita dejar huella bien sea a través de su voz o su conciencia ${ }^{1}$, sino que son escuchados por medio de portavoces que ejercen el poder hegemónico.
El uso de la palabra subalterno ha sido desarrollado desde diferentes discursos, y el concepto puede encontrarse en diversas investigaciones que datan desde la llamada Escuela de Estudios Subalternos, fundada por historiadores hindúes, la cual asume como finalidad la de priorizar y revelar el punto de vista de los subalternos. Es por ello que, a la luz de estos estudios, los discursos se relevan, con el fin de reivindicar al sujeto subalterno. Sin embargo, continuando los pasos y adelantos de los teóri$\cos$ y académicos de Oriente, algunos intelectuales latinoamericanos han creado -o por lo menos sigue en formación- un campo teórico parecido al ya descrito. Desde diversos espacios académicos (universidades e institutos latinoamericanos y europeos), se exige un espacio epistemológico para los pensadores latinoamericanos en lo que respecta a Latinoamérica; es decir, argumentan que el saber latinoamericano sobre Latinoamérica debe ser valorado por los centros de poder de Occidente.

El consenso que une a estos intelectuales $^{2}$ integrantes del Grupo Latinoamericano de Estudios Subalternos, que aparece en la década del 90, en Estados Unidos, es la necesidad de construir un mundo democrático.

Si bien el estudio de la autora se centra en la mujer como sujeto subalterno, es preciso anotar que la perspectiva de Spivak también se acoge a otros sujetos que se encuentran en condiciones subalternas con relación a los que ejercen el poder hegemónico.

2 En el grupo inicial, estaban John Beverley, lleana Rodríguez, José Rabasa, Robert Carr, Patricia Seed y Javier San Ginés. 
Siguiendo el ejemplo del grupo de la India, formaron otro, de características similares, pero referido a Latinoamérica. En 1993, publicaron un Manifiesto inaugural, en el que destacan períodos posdictatoriales, con variados procesos de redemocratización y el nuevo orden económico como consecuencia de la alineación tras políticas neoliberales y de globalización económica, que invita a "mirar hacia adelante para pensar nuevas formas emergentes de subdivisión territorial, fronteras permeables y lógicas regionales" (Mussy \& Valderrama, 2010, p. 193).

Además, consideran a la nación como un espacio de contraposición y coalición, con múltiples fracturas de lengua, raza, etnia, género y clase, en el que el subalterno aparece como un sujeto migrante. Plantean la desnacionalización y la desterritorialización del estado-nación, bajo una nueva permeabilidad de las fronteras. Por ende, cuestionan ciertas representaciones nacionales sobre las élites y los grupos subalternos. Denuncian la pobreza de la historiografía ilustrada, al no reconocer la contribución del subalterno para la creación de su propia historia. Diferencian a la nación como espacio conceptual, con relación a la nación como estado; dan a la nación una connotación más geográfica que institucional. Para el grupo:
El subalterno no es una sola cosa. Se trata, insistimos, de un sujeto mutante y migrante. Aún si concordamos básicamente con el concepto general del subalterno como masa de la población trabajadora y de los estratos intermedios, no podemos excluir a los sujetos 'improductivos', a riesgo de repetir el error del marxismo clásico[...] Necesitamos acceder al vasto y siempre cambiante espectro de las masas: campesinos, proletarios, sector formal e informal, subempleados, vendedores ambulantes, gente al margen de la economía del dinero, lumpen y exlumpen de todo tipo, niños, desamparados, etc. (Mussy \& Valderrama, 2010, p. 196).

De allí la importancia de insistir en la búsqueda de sujetos excluidos de la narrativa historiográfica tradicional, no solo por su rol en sí mismo, sino también en sus relaciones con las élites, pues es posible poner de relieve las voces silenciadas en la historia desde donde pueden mostrarse diferentes sujetos $\mathrm{y}$ realidades.

Ahora bien, teniendo en cuenta la dicotomía hegemonía versus subalternidad en la obra, es posible identificar la relación política y militar entre Somoza, Estados Unidos y el pueblo nicaragüense. Esto pone de manifiesto la dominación de fuerzas nacionales y extranjeras, que representan el control y represión de todo un país.

\section{Hegemonía política y militar}

Con el interés de estudiar la representación narrativa de la condición de subalternidad del pueblo nicaragüense, ejercida por las distintas fuerzas hegemónicas que procuran tener el control sobre ellos en nombre del progreso de la patria, se analiza en la obra el papel hegemónico de los norteamericanos y el de la dictadura somocista sobre el pueblo desde la perspectiva del narrador:

- Voy a escribir un editorial contra esos vándalos, aunque me quemen el periódico le dijo al obispo Simeón el doctor Escolástico Cisne soplándose agitadamente la cara con el sombrero, cuando salían del cementerio.

-Faltan pruebas... hasta ahora, la conducta de los soldados americanos ha sido intachable -el sabio Debayle, incrédulo, tomaba distancia de aquella exaltación.

-Yo tengo las pruebas. Un testimonio de visu -el obispo Simeón se acarició la cruz pectoral.

El sabio Debayle lo miró con desconcierto.

-De haber pruebas, sería un hecho aislado — respondió al cabo-. Sin las fuerzas del norte, este país caería en la anarquía. El caos, monseñor. (Ramírez, 1998, p. 235). 
En este fragmento, los soldados americanos, los marines, se presentan como un mecanismo de control que busca vigilar la paz y el orden del pueblo. El personaje plantea que esta presencia norteamericana, mediante la intervención militar, puede continuar garantizando la protección y seguridad de los ciudadanos. Aquí también se contextualiza, desde el punto de vista histórico, la invasión militar norteamericana como una prolongación de intentos por controlar y someter la cultura que empezó con la conquista española del continente americano, y que se ha mantenido en varios períodos de la historia de la región centroamericana. Dentro de este contexto, los marines representan una amenaza destructora para los nicaragüenses, debido a sus dos principales objetivos: garantizar sus intereses en Nicaragua, por encima de la rivalidad tradicional de los sectores oligárquicos, y la dominación del pueblo nicaragüense.

Además, dado que la intervención militar proviene directamente de Estados Unidos, este modelo político y militar se impondrá aprovechando el escaso desarrollo nacional de las fuerzas económicas y políticas locales, y su extremada subordinación a los sucesivos gobiernos norteamericanos. Tomando en consideración que las fuerzas militares norteamericanas buscaban establecerse en territorio nicaragüense a fin de reimplan- tar el orden social en momentos de crisis política interna y de velar por sus intereses, es posible inferir que, el objetivo en territorio nicaragüense es obtener el control hegemónico sobre el pueblo. Por lo tanto, este establecimiento extranjero representa en la obra una fuerza política, militar y hegemónica, que puede controlar y mantener los intereses norteamericanos.

Por otra parte, la hegemonía política y militar en la obra también se ubica en otro escenario: la dictadura somocista. En este escenario, es posible demostrar el estrecho vínculo existente entre el régimen dictatorial y el control hegemónico sobre el pueblo, que se logra mediante la represión militar de la Guardia Nacional:

Ya iba más de media hora de El barrilito cervecero, el locutor repitiendo: y ahora, para complacer al Excelentísimo Señor Presidente: $E l$ barrilito cervecero. No les bastó con las órdenes por teléfono; cuando Jorge Negrete llegó a la radio a ver qué remedio ponía, un yipón de la guardia estaba en la puerta, $\mathrm{y}$ dos agentes de seguridad en la cabina de control, emperrados, empistolados, al mando del teniente Moralitos, vigilando que no dejara de ponerse El barrilito cervecero; [...] Y El barrilito cervecero de las siete a las once de la noche, cuatro horas de El barrilito cervecero. Se acercó Jorge Negrete a Moralitos y le preguntó: «iusted cree que a estas horas el hombre siga bailando El barrilito cervecero con la quinceañera?». «No», le contestó él, frunciendo su hocico de bulldog. [...] Pero aquí me siguen poniendo $E l b a$ rrilito cervecero hasta nueva orden». (Ramírez, 1998, p. 111).

Este pasaje muestra que la dictadura somocista, representada por la presencia militarizada de la Guardia Nacional, atenta contra la autonomía del pueblo: la dominación hegemónica política y militar que se presenta es real y efectiva con respecto a la subordinación que esta ha podido infligir en la cultura nicaragüense. A modo de ejemplo, se puede mencionar que: «No les bastó con las órdenes por teléfono; [...] un yipón de la guardia estaba en la puerta, y dos agentes de seguridad en la cabina de control, emperrados, empistolados, [...] vigilando que no dejara de ponerse $E l$ barrilito cervecero» (p. 111), lo que revela cómo la Guardia Nacional intimida a través de la fuerza a los ciudadanos, con el fin de complacer los gustos del dirigente. Asimismo, se menciona que el pueblo acepta, teniendo en cuenta, por supuesto, el instrumento de fuerza que se utiliza, por lo que es posible trazar una correlación entre la subordinación permanente del pueblo y la supremacía hegemónica de la dictadura. 
En fin, la dominación hegemónica sobre el pueblo nicaragüense, se representa en la novela como una realidad que se da a partir de dos fuerzas: la presencia extranjera (marines norteamericanos) y la dictadura somocista (Guardia Nacional). Estas fuerzas ocasionan eventos violentos como consecuencia de los intereses particulares de las distintas fuerzas hegemónicas. En efecto, tales hechos revelan que la hegemonía política y militar impuesta a los nicaragüenses, ha sido una prolongada $y$ profunda represión acompañada por el ejercicio de constantes fuerzas militares.

\section{Subalternidad}

Ahora, al realizar las reflexiones en torno a hegemonía, surge la condición (oposición) de subordinación o subalternidad, vista como expresión y contraparte de la dominación encarnada o incorporada de los sujetos oprimidos. La narración de la obra deja constancia de la experiencia del estado de subordinación en que se encuentran algunos de los personajes. Es decir, el lector puede percibir cómo los propios personajes proyectan las condiciones de subalterno.

Ahora bien, la subordinación del pueblo nicaragüense por parte de las distintas fuerzas hegemónicas, es un asunto central dentro de la obra. Aunque el pueblo en su totalidad esté en un estado de subalternidad per- manente, se analiza en la obra esta condición a la luz de la historia de los siguientes personajes: Quirón y Filomela Aguirre (mejor conocida como La Caimana).

El narrador ilustra aspectos y características centrales de estos personajes: por ejemplo, Quirón (utilizado en la narración como hilo conductor entre dos momentos clave, como fueron el regreso de Rubén Darío a su natal Nicaragua y la muerte del dictador Anastasio Somoza García), quien es representado desde las primeras páginas de la novela de esta manera:

—Y tú, ¿cómo te llamas? le pregunta.

El niño sólo acierta a mirarse los pies descalzos. El sabio Debayle, impaciente, le informa que se llama Quirón.

—¿Quirón? —la asombrada interrogación de Rubén queda vibrando en el ambiente caluroso. (Ramírez, 1998, p. 28)

En este pasaje, Quirón aparece recreando la narración a partir del encuentro con el poeta Rubén Darío. Como bien puede notarse, Quirón se presenta como un personaje sin voz propia, carente de autonomía, pues, aunque en algunos pasajes interviene con enunciaciones, esta es solo una simple repetición de palabras que no permiten visibilizar su conciencia. Teniendo en cuenta lo planteado, es posible observar que sus acciones están sujetas, en este caso, a unas relaciones de mando-obediencia que se establecen bajo condiciones específicas de cada momento.

Sin embargo, este personaje también aparece en otro momento de la narración (la dictadura somocista), pues, como se enunció anteriormente, Quirón sirve de vínculo entre los dos escenarios temporales de la novela:

Quirón acostumbraba sentarse a leer. Pero todavía no estaba allí; de lo contrario, el Capitán Prío ya lo habría visto, inconfundible aún de lejos porque siempre vestía de blanco. [...] Un criadito de su padre, el que le servía la champaña, enterraba los fetos, ordenaba los instrumentos quirúrgicos. Se llama Quirón, señora, como Quirón el centauro, maestro de Esculapio. Rubén le transmitió una vez, con sus manos, el numen. ¿Rubén? ¿Rubén Darío? ¿Rubén Darío le transmitió qué? ¿en Corinto? ¿qué locura es ésa? ¿se desmayó? ¿sales de amoniaco? ¿cuándo? No ando yo creyendo en santos que orinan. (Ramírez, 1998, p. 60).

Aquí, nuevamente se plantea que su condición de subalterno no le permite hablar con su propia voz, pues es una voz que no alcanza ningún registro, sino que quien habla por él es un 
"vocero". En este caso, el narrador es el agente que gobierna el discurso y, por ende, el personaje se convierte en objeto de la narración, como consecuencia de no ser el sujeto de la enunciación.

Dado que el personaje subalterno se convierte en el objeto del discurso gobernado, puede pensarse que Quirón es utilizado por el narrador como instrumento simbólico y articulador, que aunque se caracterice por su falta de autonomía como sujeto de la enunciación, provoca con sus acciones reactivas un tejido de sucesos que permiten fundir la narración en una unidad. Lo anterior puede evidenciarse en los siguientes dos fragmentos:

El cerebro había desaparecido del escritorio. En el silencio, el hueco de la puerta devolvía el reflejo de la pintura amarilla bajo la luz eléctrica.

Quirón corría ya en desenfreno por las calles, [...] él se alejaba a galope tendido devorando las cuadras, sus rudos cascos golpeando contra el empedrado, los lomos sudorosos, hasta que desapareció de la vista de sus perseguidores. (Ramírez, 1998, pp. 278-279).

Aguardó. Ya está viejo, pero sabe que tiene que correr otra vez. Ahora respira hondo. [...] y oyen las estampidas de los disparos que se repiten de esquina en esquina cuando huye a galope por las largas cuadras de puertas cerradas hasta perderse, al fin, de vista, contra su pecho la medusa de los testículos, otra medusa como aquella otra de hace tiempo, que se mueve, despierta, animosa, al ritmo de su carrera, los rudos cascos golpeando contra el empedrado, los lomos sudorosos, hacia el prostíbulo desierto, hacia la fuente de noche y de olvido, hacia la nada. (pp. 368-369).

Los apartes detallan los momentos en el que Quirón participa de las dos historias: por un lado, el robo del cerebro de Darío; y, por el otro, el robo de los testículos de Rigoberto. Es justo recordar que, Quirón, a quien el poeta Rubén Darío había "traspasado" el numen de las musas, logró burlarse de las autoridades militares de la época, y apropiarse del cerebro llevándolo a enterrar al jardín trasero del prostíbulo de La Caimana. Lo mismo hace, tiempo después, con los testículos de Rigoberto López, contra quien se había ejecutado la orden de cortárselos luego que este cometiera el magnicidio contra Anastasio Somoza. Quirón aprovecha nuevamente el descuido de la autoridad, en este caso, los soldados de la Guardia Nacional, y se apodera de los órganos para escapar hacia el jardín del burdel de La Caimana y enterrarlo junto al cerebro de Darío. Con esto, podría explicarse el papel de Quirón como sujeto subalterno y, a su vez, como objeto sim- bólico, pues es a quien utiliza el narrador como estrategia efectiva para articular en un sistema unificador su propio discurso.

Por otro lado, en la obra también aparece Filomela Aguirre, La Caimana. Este personaje, al igual que Quirón, ayuda a hilar los dos momentos temporales de la narración, que poco a poco se van entremezclando, trenzando, hasta establecer una interacción que le da unidad a la historia. Filomela Aguirre «a quien la fama conocerá más tarde como La Caimana por esos dientecitos filosos» (Ramírez, 1998, p. 186) es un personaje subalterno que está marcado por doble partida: por lo femenino y por lo periférico:

Entre patriarcado e imperialismo, entre la constitución del sujeto y la formación del objeto, la figura de la mujer desaparece, no en una nada limpia, sino en una violenta ida y vuelta que es la figuración desplazada de la "mujer del tercer mundo" atrapada entre la tradición y la modernización, el culturalismo y el desarrollo (Spivak, 2009, p. 116).

En otras palabras, la subalternidad de los personajes periféricos y femeninos que se profesa desde los estudios teóricos poscoloniales, se encuentran silenciados ante la imposibilidad de participar como agentes dinámicos, pues su condición marginal les impide 
visibilizarse por sí mismos, ya que parte de una representación ajena que apela a la imaginación colonialista a través de la cual se pretende hablar por estos sujetos. Por consiguiente, en el caso particular de $L a$ Caimana, el sujeto periférico es evidenciado mediante la aceptación voluntaria del poder hegemónico:

La Caimana: (jadea). Filomela Aguirre, a sus órdenes. ¡Viva Somoza! ¡Viva el Partido Liberal!

Locutor: ¿Qué le dijo al Señor Presidente?

La Caimana: Que no se olvide que falta una escuela en el Barrio de la Ermita de Dolores. Hay multitud de niños que perecen por falta de profesor. Eso le dije, y el prometió cumplir. (Ramírez, 1998, p. 183).

Si bien es importante anotar que el poder dominante no solo «se explica a través de la imposición forzada, sino que además se institucionaliza a través del sistema de propiedad y leyes; y se justifica moralmente $-y$ por ende se asimila como deseablea través de la religión y las tradiciones» (Guha \& Spivak 1988, p. 44), o como un proceso que cuenta con la aprobación de los sujetos subalternos; podría decirse entonces que, La Caimana, sujeto dominado, resalta su subalternidad como una experiencia asimilada que da origen a un proceso de subjetivación política ${ }^{3}$ consciente, sin necesidad de un proceso forzoso.

También, es preciso anotar que, aunque el argumento general de la historia apunta al silenciamiento estructural de lo subalterno dentro de la narrativa, es claro que, el sujeto de $L a$ Caimana "habla" físicamente a través de un formato o recurso que utiliza el narrador para representar la voz del personaje (en forma de guion teatral); sin embargo, no adquiere estatus dialógico, esto quiere decir que, no es un sujeto que ocupa una posición discursiva desde la que puede hablar o responder. Este silenciamiento, entonces, no se da en el plano de la existencia, sino en el plano de la representación.

La posición subalterna también se ve reflejada en la condición del sexo/género de La Caimana. Este estado se ilustra en la narración, desde el momento en que es entregada en un hospicio para niños huérfanos cuando era apenas una niña:
- No puedo - le dijo tras retirarse de la lumbre-. En el hospicio sólo viven niños varones.

-Puede cortarle el pelo suplicó El Dragón Colosal.

- Me lo pide Nuestra Señora... -caviló-; pero, ¿qué puedo hacer?

— ¿Quién se va a dar cuenta, su eminencia? - dijo El Dragón Colosal y puso una rodilla en tierra.

—Eminencia no soy - lo reprendió suavemente el santo Mardoqueo; luego, dirigió su mirada a la niña-. ¿Cómo te llamas?

—Filomela —contestó El Dragón Colosal, y humilló la otra rodilla - Si gusta, puede llamarla Filomelo. (Ramírez, 1998, pp. 195-196).

Se observa que el personaje es víctima de un sistema hegemónico masculino, que privilegia y prioriza a los hombres por encima de las mujeres. Esto afirma que este sistema sexo/ género basado en la subalternidad de las mujeres -refiérase a patriarcado, matriz heterosexual, o machismo-, funciona como elemento estabilizador de la jerarquía social, en este caso, como una forma de categoriza-

3 Que de la subjetivación se diga que es política, quiere decir que hay condiciones exteriores por las que un ser, no por cuenta propia (aunque lo haga con su consentimiento), entra en un proceso en el que llega a ser otro de lo que es (what he is), pero en el que puede sin embargo reconocerse como inmerso en un movimiento que tiene que ver singularmente con el quien que es (who he is). Ver Éttiene, T. (2012). De la subjetivación política. Althusser/Rancière/Foucault/Arendt. Revista de Estudios Sociales RES, (37), 36-49. 
ción de la diferencia. Además, en la obra se evidencia que $L a$ Caimana es víctima del abuso sexual por parte de los huérfanos (hombres) del hospicio:

[...] de regreso de una audiencia con el obispo Simeón, encontró que los huérfanos habían violado a la niña. Llorando de rabia, el lamparón de sangre todavía húmedo en el sayal, los amagaba entre insultos feroces, en la mano la broca de pirotécnico que había corrido a buscar en el morral apenas pudo escaparse de ellos. Ya había alcanzado a herir a uno en la barriga, y el santo Mardoqueo logró al fin desarmarla, defendiéndose de sus dientecitos y cercándola entre súplicas. (Ramírez, 1998, pp. 198-199).

Este pasaje evidencia la desgracia del personaje, manifestado en el uso y abuso que hacen de ella los huérfanos del hospicio, como cuerpo sexual. Un comportamiento en extremo violento en el que el hombre toma posesión del cuerpo de la mujer, como objeto. Estas marcas violentas alcanzan su punto culminante con la decisión que toma, posteriormente, La Caimana de convertirse en hombre:

Y puesto que quería hacerse rico a cualquier precio, Justo Pastor Gonzaga lo llevó a ver a La Caimana, que quería ser hombre a cualquier precio. $\mathrm{Y}$ el troquel, junto con la fragua de fundición, las barras de estaño y cobre, y los saquitos de limadura de plata para acuñar los símiles de las monedas, fueron trasladados a un cobertizo del patio de juegos de Las Animas Benditas, una vez alcanzado el acuerdo entre las partes. (Ramírez, 1998, p. 320).

La injusticia y violencia de género provoca este cambio en el personaje, pues a toda costa decide convertirse en hombre usando medios delictivos, como la falsificación de monedas (al lado de Justo pastor Gonzaga y Anastasio Somoza), donde es descubierta, y puesta presa tras guardar silencio para que sus cómplices se salvaran. Por lo que más tarde, es recompensada con la operación del cambio de sexo a cargo del sabio Debayle:

La ansiada mano de Salvadorita volvía a aparecer lejana. Pero La Caimana insistía en ser hombre. De manera que el mariscal hubiera seguido atrapado entre los dientes de su perra suerte, azotando con sus suelas de goma las calles de León en busca de excusados que alumbrar, sino ha sido por aquella terquedad. $\mathrm{Y}$ le escribió una carta al sabio Debayle, proponiéndole la operación. (Ramírez, 1998, p. 322).

La decisión de convertirse en hombre es insistente en el personaje, podría pensarse que opera como una reacción en contra del abuso cometido y en contra del sistema dominante.
Resulta entonces obvio plantear que la condición subalterna de sexo/género forma parte fundamental del consenso en la hegemonía, manifestada, por ejemplo, tanto por la discriminación que sufre cuando era apenas una niña, como por el abuso y la violación de la que es víctima más tarde.

Así, los personajes de Quirón y La Caimana son configurados a través del discurso del narrador $\mathrm{y}$, aunque están representados de manera pasiva frente a su posición de subalternos, se constituyen en personajes unificadores y tejedores de la historia y, sobre todo, confieren una significación poscolonial importante al texto narrativo, puesto que, al contradecir con sus acciones el discurso de la historia, neutralizan el constructo binario al desestabilizar los entes hegemónicos de la época.

\section{Conclusión}

Así, de esta manera se examina la relación dicotómica entre hegemonía $y$ subalternidad, pues se analiza la condición subalterna de la sociedad nicaragüense, examinando cómo el poder hegemónico de las instituciones militares y políticas someten, mediante mecanismos de fuerza, a todo un país con el fin de proteger sus intereses particulares. Al respecto, se constata que la presencia norteamericana y la dictadura somocista tienen un vínculo estrecho con el logro 
del control hegemónico sobre los ciudadanos, derivado de la intervención militar opresiva de los marines y los de la Guardia Nacional. También, en relación a la subalternidad, se revela la exclusión de la voz del otro (subalterno), desde el plano de la representación. Por lo tanto, aunque se constata que personajes como Quirón y Filomela Aguirre La Caimana no tienen voz propia en la novela, lo cual demuestra que están en una posición narrativa de subalternidad, sí cumplen una función determinante -desde el plano de la existencia-, pues son los hilos conductores de los dos ejes narrativos de la novela que edifican una nueva imagen de la realidad, que trasciende las concepciones excluyentes y se justifican bajo la desmitificación de los grandes personajes históricos.

Para finalizar, este análisis de Margarita, está linda la mar busca, por un lado, mostrar la (re)creación de otra Historia, desde otra mirada, desde una visión desconfiada, crítica y deconstructiva. A partir de aquí, la obra intenta recuperar el pasado, pero reinventándolo, es decir, apropiándose de toda esta materia histórica y transformándola en texto, mediante un posicionamiento que permita redefinir lineamientos y explicaciones de un presente o de un futuro posible. La novela entonces, es memoria, testimonio y reflejo de un pasado histórico que es también proceso social y conciencia intelectual de un presente conflictivo. Y, por el otro, busca con los postulados de los estudios poscoloniales, demostrar que los temas y perspectivas narrativas revelan la huella colonial como una relación binaria que subsiste en el presente en forma de relaciones desiguales. Por lo tanto, se espera que este análisis haya revelado el conflicto y, además, la necesidad -no solo de neutralizar, sino- de deconstruir los sistemas binarios que contribuyen a descolonizar una construcción ideológica-histórica.

\section{Referencias}

Ashcroft, B., \& Ahluwalia, P. (2001). Edward Said. London: Routledge.

Éttiene, T. (2012). De la subjetivación política. Althusser/Rancière/Foucault/Arendt. Revista de Estudios Sociales RES, (37), 36-49.

Guha, R., \& Spivak, G. (1988). Selected Subaltern Studies. Oxford: Oxford University Press.

Mussy, L., \& Valderrama, M. (2010). Historiografía Postmoderna. Conceptos, figuras, manifiestos: Grupo Latinoamericano de Estudios Subalternos "Manifiesto Inaugural”. Santiago: Ediciones Universidad Finis Terrae-RIL Editores.

Pons, M. (1999). La novela histórica del fin del siglo XX: de inflexión literaria y gesto politico a retórica de consumo. Perfiles latinoamericanos: revista de la Facultad Latinoamericana de Ciencias Sociales, (15), 139-169.

Ramírez, S. (1998). Margarita, está linda la mar. España: Alfaguara. 
Souza, R. (1988). La historia en la novela hispanoamericana moderna. Bogotá: Tercer Mundo Editores.

Spivak, G. (2009). ¿Puede hablar el subalterno? Barcelona: Edición crítica a cargo de Asensi, Manuel. MACBA. 
la palabra 